\title{
Mechanism of $\mathrm{Al}^{3+}$-Catalyzed Transamidation of Unactivated Secondary Carboxamides.
}

\author{
Justin M. Hoerter, Karin M. Otte, Samuel H. Gellman* and Shannon S. Stahl* \\ Department of Chemistry, University of Wisconsin-Madison, 1101 University Avenue, \\ Madison, WI 53706
}

\section{Table of Contents}

Pages

Experimental: General Considerations

S2

General procedure for concentration dependence kinetics.

S2

Representative stoichiometric NMR study: NMR scale reaction of $\mathrm{Al}_{2}\left(\mathrm{NMe}_{2}\right)_{6}$ (1) with amide 2 .

S2

Degenerate transamidation: NMR scale reaction of $\mathbf{1}$ with $\mathbf{2}$ and $\mathbf{5}$.

S2

Degenerate transamidation: NMR scale reaction of $\mathbf{1}$ with $\mathbf{3}$ and $\mathbf{4}$.

S3

Transamidation: NMR scale reaction of $\mathbf{1}$ with $\mathbf{2}$ and $\mathbf{3}$ at $90{ }^{\circ} \mathrm{C}$.

S3

In situ IR spectroscopic analysis of the titration of $\mathbf{2}$ and $\mathbf{3}$ against $\mathbf{1}$.

S3

Figure S1: FT-IR spectra of diagnostic Al(III)-amidate stretches at different stoichiometric concentrations of amide 2 with precatalyst 1.

Figure S2: FT-IR monitored titration of $\mathrm{Al}_{2}\left(\mathrm{NMe}_{2}\right)_{6}(\mathbf{1})$ with amide $2 . \quad$ S5

Figure S3: ${ }^{1} \mathrm{H}$ NMR monitored titration of $\mathrm{Al}_{2}\left(\mathrm{NMe}_{2}\right)_{6}(\mathbf{1})$ with amide 2 . S6

Figure S4: gHMBC experiment illustrating 3-bond coupling between CO and benzylic methylene resonances for Al(III)-amidate $\mathbf{6 a}$.

Figure S5: ${ }^{1} \mathrm{H}$ NMR spectra of degenerate transamidation (amide 2 and amine 5 catalyzed by 1) plotted with transamidation.

Figure S6: ${ }^{1} \mathrm{H}$ NMR spectra of degenerate transamidation (amide $\mathbf{3}$ and amine $\mathbf{4}$ catalyzed by $\mathbf{1})$ plotted with transamidation. 


\section{Experimental}

General Considerations. All syntheses and sample preparations were performed following Schlenk techniques or in a nitrogen atmosphere glovebox. Toluene- $\mathrm{d}_{8}$ was dried over sodium and benzophenone and distilled prior to use. Solvents were dried with activated alumina purification columns. NMR spectral data was obtained using a Bruker AC-300, Varian Mercury 300 and Varian UNITY 500 spectrometers. ${ }^{1} \mathrm{H}-\mathrm{NMR}$ spectra were referenced to residual $\mathrm{C}_{6} \mathrm{D}_{5} \mathrm{CD}_{2} \mathrm{H}$ (2.05 ppm), and ${ }^{13} \mathrm{C}$ NMR spectra were referenced to the $\mathrm{C}_{6} \mathrm{D}_{5} C \mathrm{D}_{3}$ resonance $(20.4 \mathrm{ppm})$. In situ infrared spectra were obtained with a Hamilton Sundstrand Chemeye Diamond 20 FTIR spectrometer equipped with an Axiom DPR207 ATR probe. Gas Chromatography was performed with a Shimadzu GC-17A gas chromatograph equipped with a $15 \mathrm{~m}$ RTX-5 capillary column (Restek). $N$-Benzylheptanamide and $N$-(2ethylhexyl)heptanamide were synthesized following published literature procedures. $\mathrm{The} \mathrm{Al}_{2}\left(\mathrm{NMe}_{2}\right)_{6}$ catalyst was purchased from Strem and used as received. Benzylamine and 2-ethylhexylamine were purchased from Aldrich and distilled from $\mathrm{CaH}_{2}$ before use. Isotopically labeled analogs, $N$ Benzylheptanamide- $\mathrm{d}_{1}$ and 2-ethylhexylamine- $\mathrm{d}_{2}$, were prepared from modified literature methods. ${ }^{1}$

General procedure for concentration dependence kinetics. A representative procedure used to determine initial rates for kinetics studies is given with a specific example, the effect of catalyst concentration on reaction rate. Standard toluene solutions of the aluminum catalyst 1 (41 mM, $0.0664 \mathrm{~g}$ in $5.0 \mathrm{~mL}$ toluene), amide 2 (0.83 M, $1.8249 \mathrm{~g}$, in $10.0 \mathrm{~mL}$ toluene), amine 3 (0.83 M, $1.36 \mathrm{ml}, 0.789$ $\mathrm{g} / \mathrm{mL}$ in $10.0 \mathrm{~mL}$ toluene) and internal standard triphenylmethane $(0.42 \mathrm{M}, 1.0171 \mathrm{~g}$, in $10.0 \mathrm{~mL}$ toluene) were prepared in a glovebox. In a 12-well temperature controlled reactor (IKA RCT fitted with an IKA ETS-04 controller), $1.0 \mathrm{ml}$ each of the stock solutions for 2, 3, and internal standard were premixed with $1.0 \mathrm{~mL}$ toluene. The solution was equilibrated at $90{ }^{\circ} \mathrm{C}$ with stirring for 20 minutes. The reaction was initiated by injection of $1.0 \mathrm{~mL}$ of the catalyst stock solution. Beginning immediately after initiation of the reaction $100 \mu \mathrm{L}$ aliquots were withdrawn from the reaction mixture at 2 min intervals and quenched by dilution in $2 \mathrm{~mL}$ of toluene at RT. For full time-course studies, the first $5 \mathrm{~h}$ were monitored by taking a sample every $30 \mathrm{~min}$, the next $5 \mathrm{~h}$ were monitored by taking a sample every $1 \mathrm{~h}$, and a final time point was taken at $24 \mathrm{~h}$. The extent of conversion was evaluated by gas chromatography (GC) with integrations of the amide peaks relative to the internal standard.

Representative stoichiometric NMR study: NMR scale reaction of $\mathrm{Al}_{2}\left(\mathrm{NMe}_{2}\right)_{6}(1)$ with amide 2 . Stock solutions of 1 (1.7 M, $0.2651 \mathrm{~g}$ in $1.0 \mathrm{~mL}$ toluene- $\left.\mathrm{d}_{8}\right), 2$ (1.7 M, $0.4304 \mathrm{~g}$ in $3.0 \mathrm{~mL}$ toluene- $\mathrm{d}_{8}$ ) and internal standard (1,3,5-trimethoxybenzene, $1.7 \mathrm{M}$, ) in toluene- $\mathrm{d}_{8}$. Four NMR tubes were prepared with 2, 4, 6, and 10 (representing 10\% catalyst loading) equivalents of 2 (where 1 equiv. equals $50 \mu \mathrm{L}$,


and ${ }^{13} \mathrm{C}$ NMR spectra (Figure S3 and 4 respectively) were obtained at room temperature on a $300 \mathrm{MHz}$ instrument followed by experiments at $90{ }^{\circ} \mathrm{C}$ on a $500 \mathrm{MHz}$ spectrometer.

Degenerate transamidation: NMR scale reaction of 1 with 2 and 5. Stock solutions of 1 (0.83 M, $0.2651 \mathrm{~g}$, in $2.0 \mathrm{~mL}$ toluene- $\left.\mathrm{d}_{8}\right), 2\left(0.83 \mathrm{M}, 0.5474 \mathrm{~g}\right.$, in $3.0 \mathrm{~mL}$ toluene- $\left.\mathrm{d}_{8}\right), 5(0.83 \mathrm{M}, 0.1784 \mathrm{~g}$, in 2.0 mL toluene- $\left.\mathrm{d}_{8}\right)$ and internal standard (1,3,5-trimethoxybenzene, $\left.0.83 \mathrm{M}\right)$ in toluene- $\mathrm{d}_{8}$ were prepared in a glovebox. A 5mm NMR tube was loaded with $200 \mu \mathrm{L}$ each of the solutions 2, 5 and IS, followed by $40 \mu \mathrm{L}$ of solution 1 and the tube diluted to a total volume of $1.0 \mathrm{~mL}$ with toluene- $\mathrm{d}_{8}$ (final

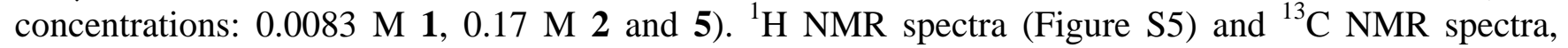
obtained at room temperature, confirm the consumption of three equivalents $\mathbf{2}$ to form $\mathbf{6 a}$ together with the release of dimethyl amine. ${ }^{1} \mathrm{H},{ }^{13} \mathrm{C}$ and $\mathrm{HMBC}$ NMR spectra were also obtained at $90{ }^{\circ} \mathrm{C}$ to confirm the identity of the trisamidate $\mathbf{6 a}$.

\footnotetext{
${ }^{1}$ Smith, J. K.; Bergbreiter, D. E.; Newcomb, M., J. Org. Chem. 1985, 50, 4549.
} 
Degenerate transamidation: NMR scale reaction of 1 with 3 and 4. Stock solutions of 1 (8.3 M, $0.2651 \mathrm{~g}$, in $2.0 \mathrm{~mL}$ toluene- $\left.\mathrm{d}_{8}\right), 3\left(8.3 \mathrm{M}, 0.2152 \mathrm{~g}\right.$, in $2.0 \mathrm{~mL}$ toluene- $\left.\mathrm{d}_{8}\right), 4(8.3 \mathrm{M}, 0.2010 \mathrm{~g}$, in $1.0 \mathrm{~mL}$ toluene- $\left.\mathrm{d}_{8}\right)$ and internal standard (1,3,5-trimethoxybenzene, $8.3 \mathrm{M}$ ) in toluene- $\mathrm{d}_{8}$ were prepared in a glovebox. A 5mm NMR tube was loaded with $200 \mu \mathrm{L}$ each of stock solutions 3, 4 and IS, followed by $40 \mu \mathrm{L}$ of stock solution 1 and the tube diluted to a total volume of $1 \mathrm{~mL}$ (Final concentration: 0.083 M 1, $0.17 \mathrm{M} 3$ and 4). ${ }^{1} \mathrm{H}$ (figure S6) and ${ }^{13} \mathrm{C}$ NMR spectra were obtained at room temperature and confirming consumption of three equivalents 4 to form $6 \mathbf{b}$ releasing dimethyl amine. ${ }^{1} \mathrm{H},{ }^{13} \mathrm{C}$ and HMBC NMR spectra were also obtained at $90^{\circ} \mathrm{C}$ to confirm the identity of the trisamidate $\mathbf{6 b}$.

Transamidation: NMR scale reaction of 1 with 2 and 3 at $90{ }^{\circ} \mathbf{C}$. To a $5 \mathrm{~mm}$ NMR tube were added 1 (5.3 mg, $0.033 \mathrm{mmol}$ ), 2 (36.5 mg, $0.17 \mathrm{mmol}$ ), 1,3,5-trimethoxybenzene (IS, $14.0 \mathrm{mg}, 0.0083 \mathrm{mmol}$ ), and toluene- $\mathrm{d}_{8}(0.3 \mathrm{~mL})$. In a separate vial, $3(21.5 \mathrm{mg}, 0.17 \mathrm{mmol})$ was weighed and diluted with toluene- $\mathrm{d}_{8}(0.1 \mathrm{~mL})$. The amine 3 was pipetted from the vial into the NMR tube and the vial was rinsed four times to ensure complete transfer of 3. In preparation of the experiment, the $500 \mathrm{MHz} \mathrm{NMR}$ spectrometer was preshimmed on toluene- $\mathrm{d}_{8}$ at $90{ }^{\circ} \mathrm{C}$, and the experiment was initiated after $10 \mathrm{~min}$ time in the probe to allow for temperature equilibration. A total of $100{ }^{1} \mathrm{H}$ spectra were collected in an array every 5 min (4 scans, d1 = $25 \mathrm{~s}$ ).

In situ IR spectroscopic analysis of the titration of 2 and 3 against 1 . An experiment identical to the one above was conducted with a syringe loaded with a $1: 1$ ratio of 2 and 3 (1.0 M stock solution, $2.1916 \mathrm{~g} 2$ and $1.2924 \mathrm{~g} 3$ in $10 \mathrm{~mL}$ ) titrated against 1 ( $0.17 \mathrm{M}, 0.3184 \mathrm{~g}, 0.042 \mathrm{mmol})$. Data illustrating both the spectra at specific relative concentrations are presented in Figure S1 and the time-course traces of specific wavenumbers (Figure S2). 


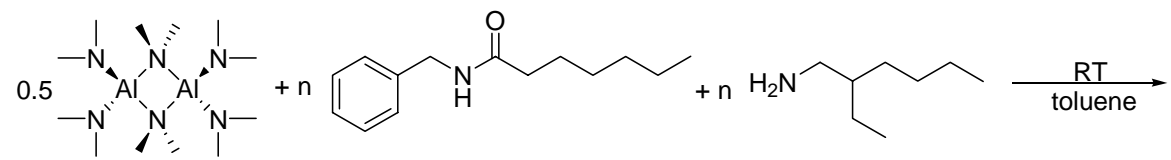

1

After one equivalent of $\mathbf{2}$ added per aluminum.<smiles>CCCCCCCC(=O)NCc1ccccc1</smiles>

After two equivalents of 2 added per aluminum.<smiles>CCCCCCC(=O)NCc1ccccc1</smiles>

After three equivalents of $\mathbf{2}$ added per aluminum.
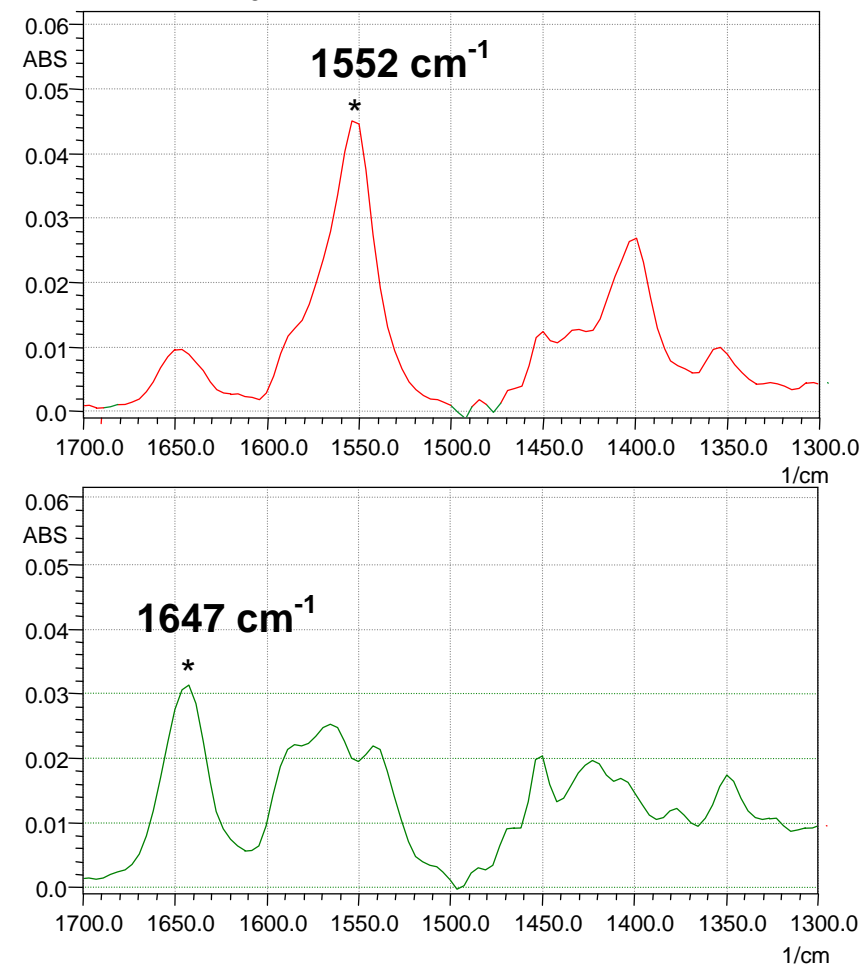<smiles>CCCCCCC(=O)NCc1ccccc1</smiles>

After six equivalents of $\mathbf{2}$ added per aluminum.
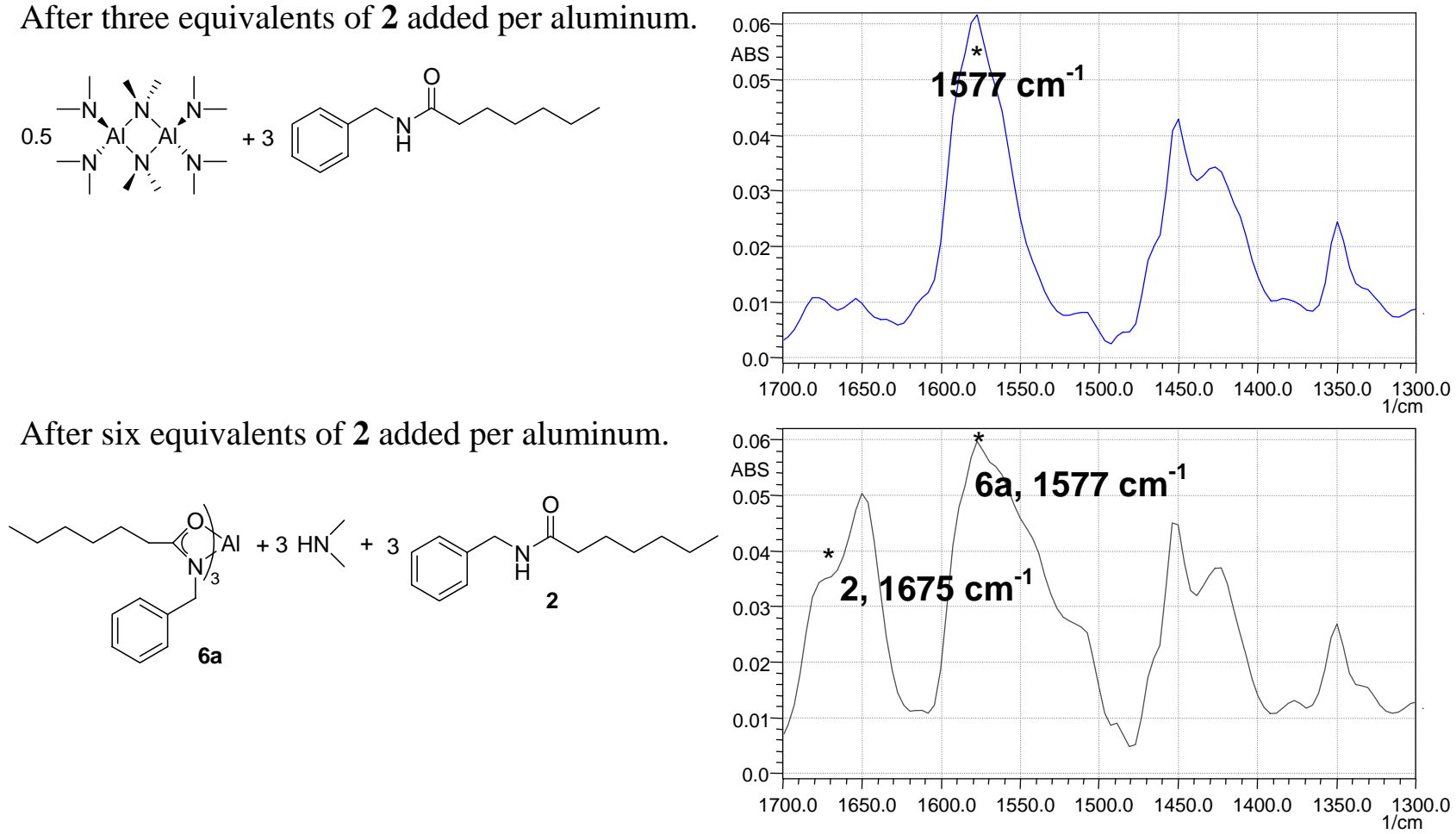

Figure S1. Selected spectra from the titration of a premixed solution of $\mathbf{2}$ and $\mathbf{3}$ against $\mathbf{1}$ as observed by an in situ ATR probe at specific concentration ratios. Diagnostic amide I and amide II resonances are highlighted for the species in solution. A $2.5 \mathrm{~mL}$ solution of $\mathbf{1}$ was titrated with a $2.5 \mathrm{~mL}$ solution of 2 and 3, with [1], [2] and [3] = 0.33 M. 



Figure S2. Single wavenumber time traces for the titration of a premixed solution of $\mathbf{2}$ and $\mathbf{3}$ against $\mathbf{1}$ as observed by and in situ ATR probe plotted against each other. A $2.5 \mathrm{ml}$ solution with [1], [2] and [3] $=0.33 \mathrm{M}$. 


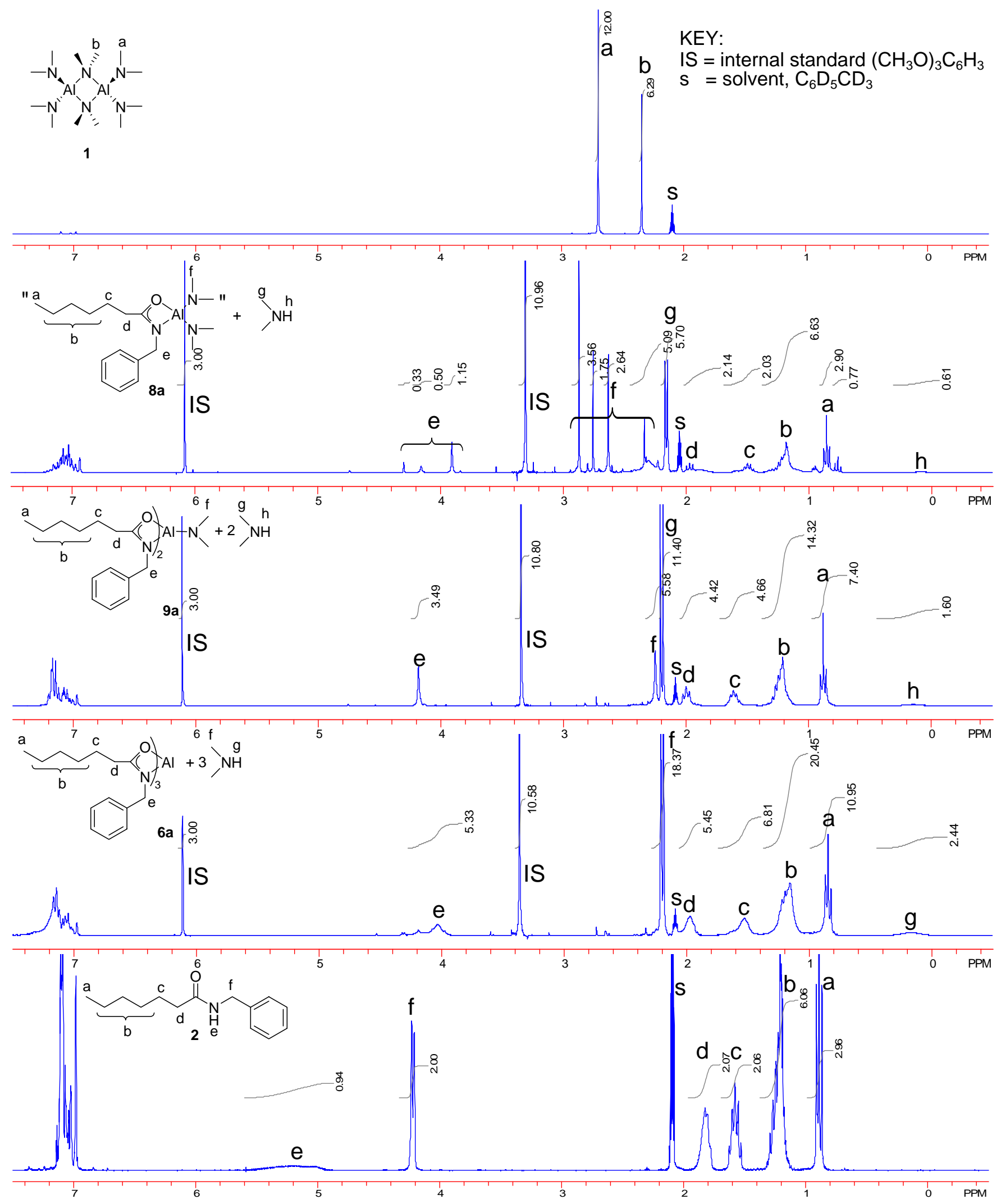

Figure S3. A series of ${ }^{1} \mathrm{H}$ NMR spectra with varying concentrations of $\mathbf{1}$ and $\mathbf{2}$ are plotted to illustrate the characterization of aluminum amidate complexes, 8a, 9a and $\mathbf{6 a}$. One equivalent corresponds to $0.082 \mathrm{M}\left(1.0 \mathrm{~mL}\right.$ of toluene- $\left.\mathrm{d}_{8}\right)$. Also shown are $\mathrm{Al}_{2}\left(\mathrm{NMe}_{2}\right)_{6}$ and amide 2 . 


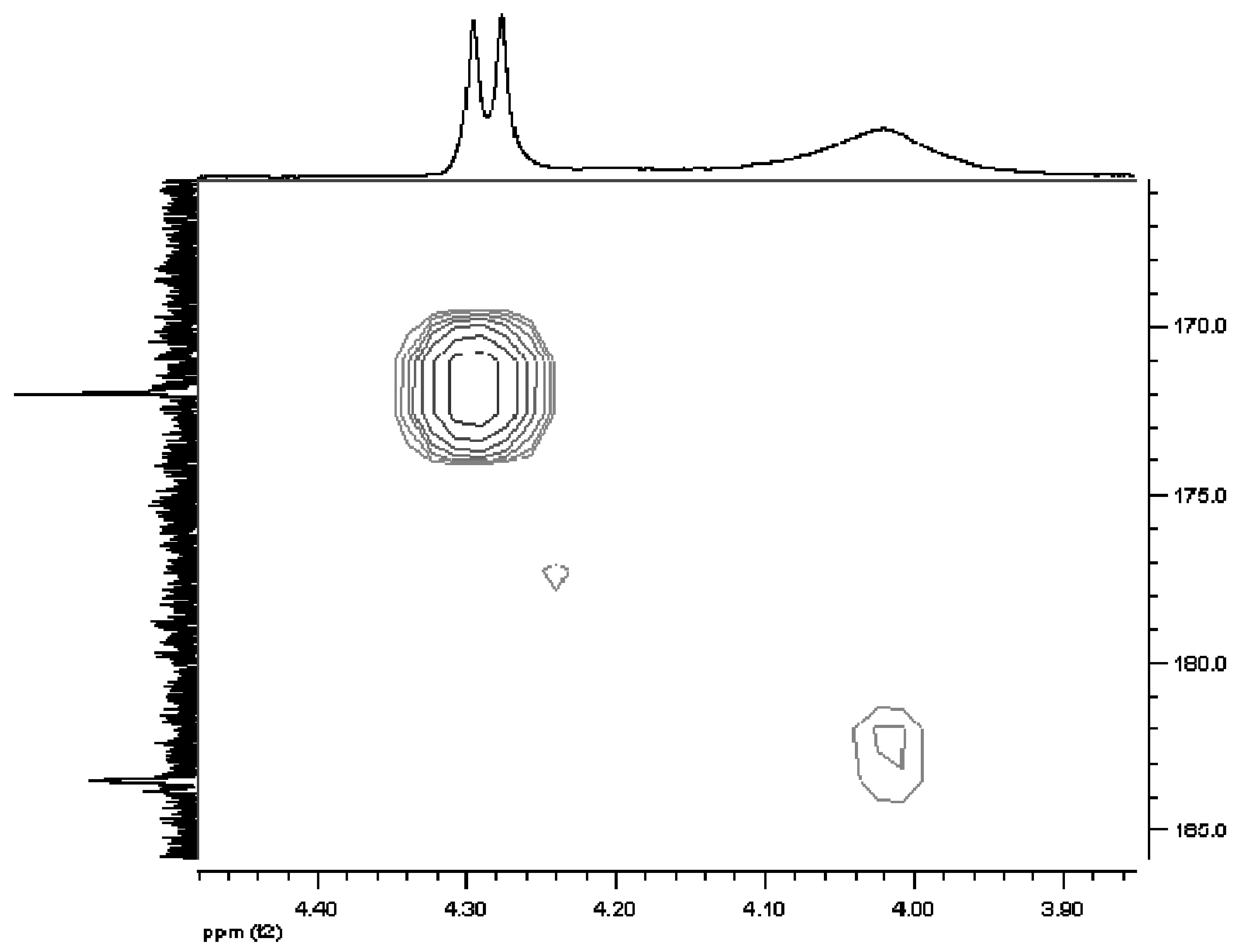

Figure S4. A zoomed in gHMBC NMR spectra of the reaction mixture containing 1 (0.0082 $\mathrm{M}$ in 1.0 mL toluene- $\left.\mathrm{d}_{8}\right)$ and 10 equivalents of 2 and $3\left(0.082 \mathrm{M}\right.$ in $1.0 \mathrm{~mL}$ toluene- $\left.\mathrm{d}_{8}\right)$ illustrating the 3-bond coupling between the carbonyl carbon and the methylene protons of the benzyl group. 
$28{ }^{\circ} \mathrm{C}$ benzylheptamide 2 and benzylamine $\mathbf{5}$

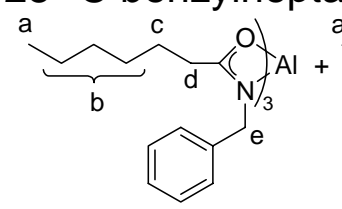

$6 a$

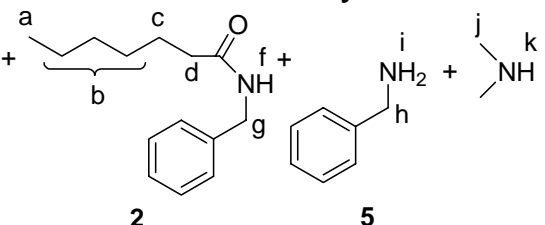

KEY:

$\mathrm{S}=$ solvent, $\mathrm{C}_{6} \mathrm{D}_{5} \mathrm{CD}_{3}$

IS = internal standard $\left(\mathrm{CH}_{3} \mathrm{O}\right)_{3} \mathrm{C}_{6} \mathrm{H}_{3}$

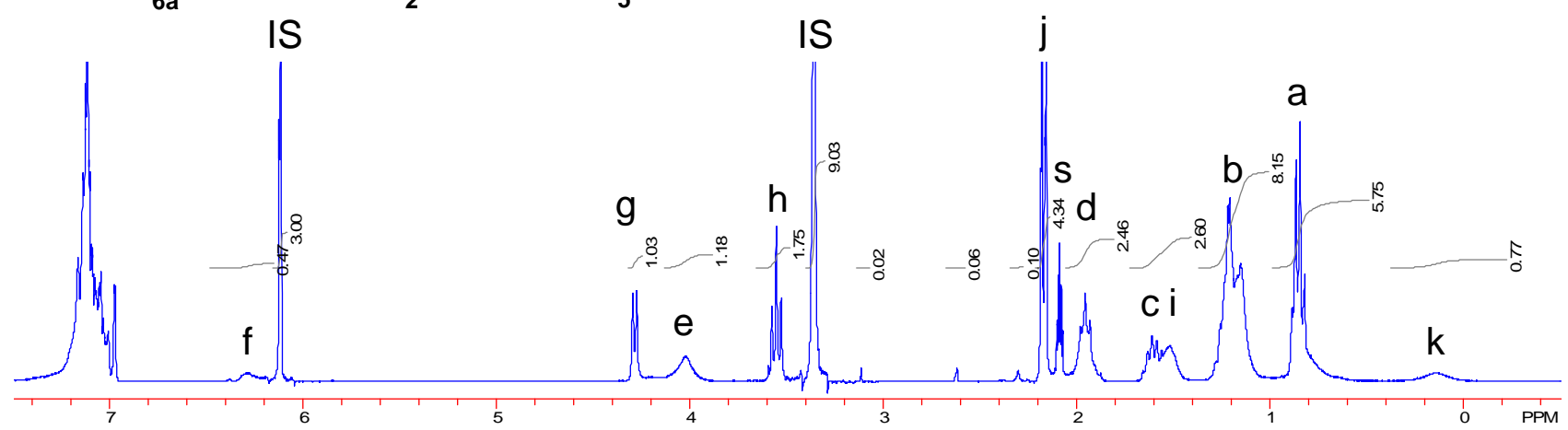

$90{ }^{\circ} \mathrm{C}$ benzylheptamide 2 and benzylamine 5
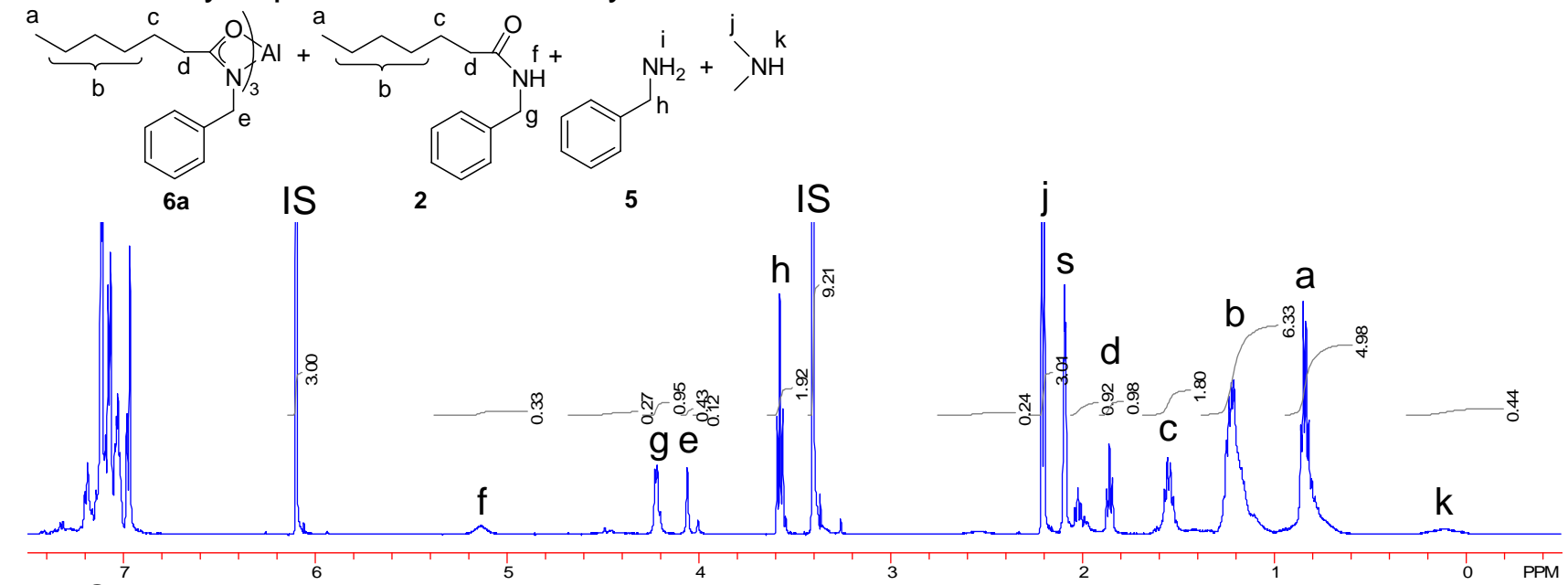

$90{ }^{\circ} \mathrm{C}$ transamidation

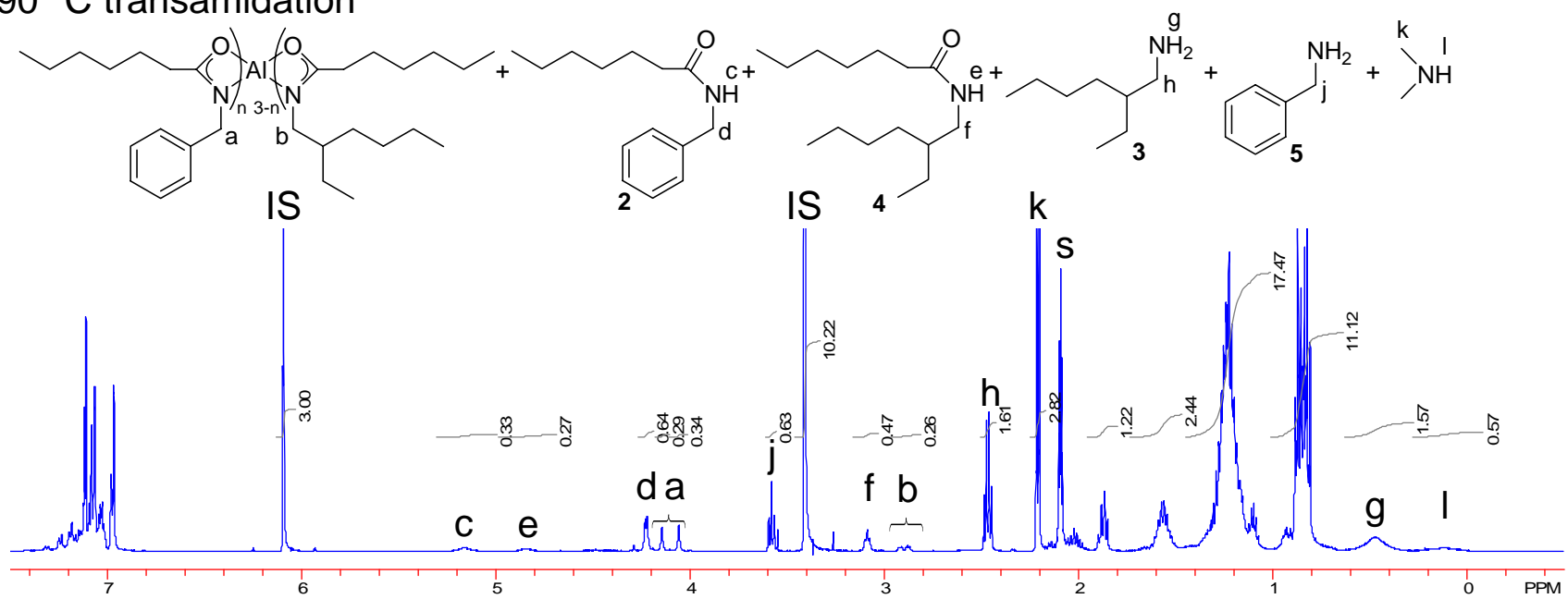

Figure S5. A stacked plot containing two ${ }^{1} \mathrm{H}$ NMR spectra of a degenerate reaction mixture $(\mathbf{1}, \mathbf{2}$, and 5) one shown on the top at $28{ }^{\circ} \mathrm{C}$ and another in the middle at $90{ }^{\circ} \mathrm{C}$ are displayed. The bottom ${ }^{1} \mathrm{H}$ NMR spectra illustrates a sample transamidation reaction mixture at $90^{\circ} \mathrm{C}$. Conditions: amides ( 2 and 3 ) and amines (4 and 5), $0.082 \mathrm{M}\left(1.0 \mathrm{~mL}\right.$ of toluene- $\left.\mathrm{d}_{8}\right) ; 10.0082 \mathrm{M}$ (1.0 mL of toluene- $\left.\mathrm{d}_{8}\right)$. 
$28^{\circ} \mathrm{C}$ 2-ethylhexylheptylamide 3 and 2-ethylhexylamine 4

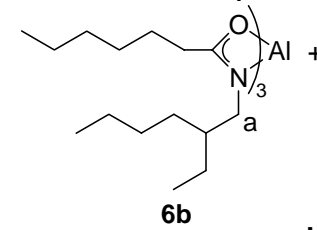

$6 b$

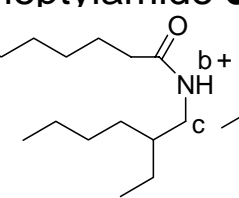

4

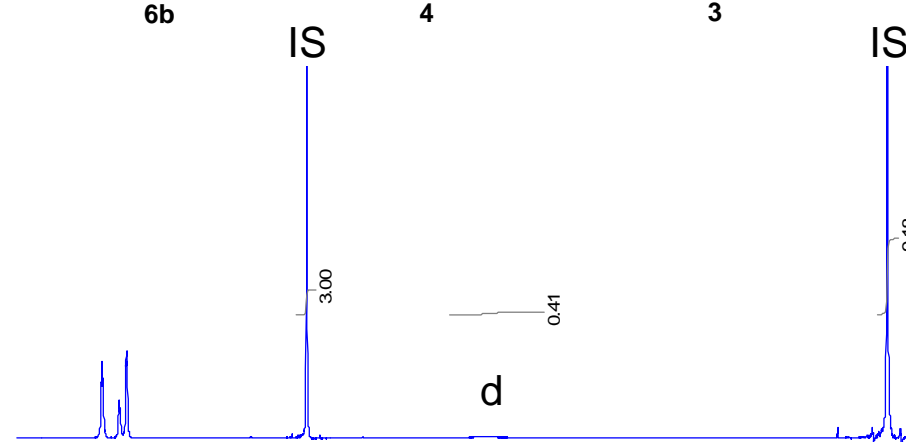

5
KEY:

$\mathrm{S}=$ solvent, $\mathrm{C}_{6} \mathrm{D}_{5} \mathrm{CD}_{3}$

IS = internal standard $\left(\mathrm{CH}_{3} \mathrm{O}\right)_{3} \mathrm{C}_{6} \mathrm{H}_{3}$

\section{$90{ }^{\circ} \mathrm{C}$ 2-ethylhexylheptylamide $\mathbf{3}$ and 2-ethylhexylamine 4}
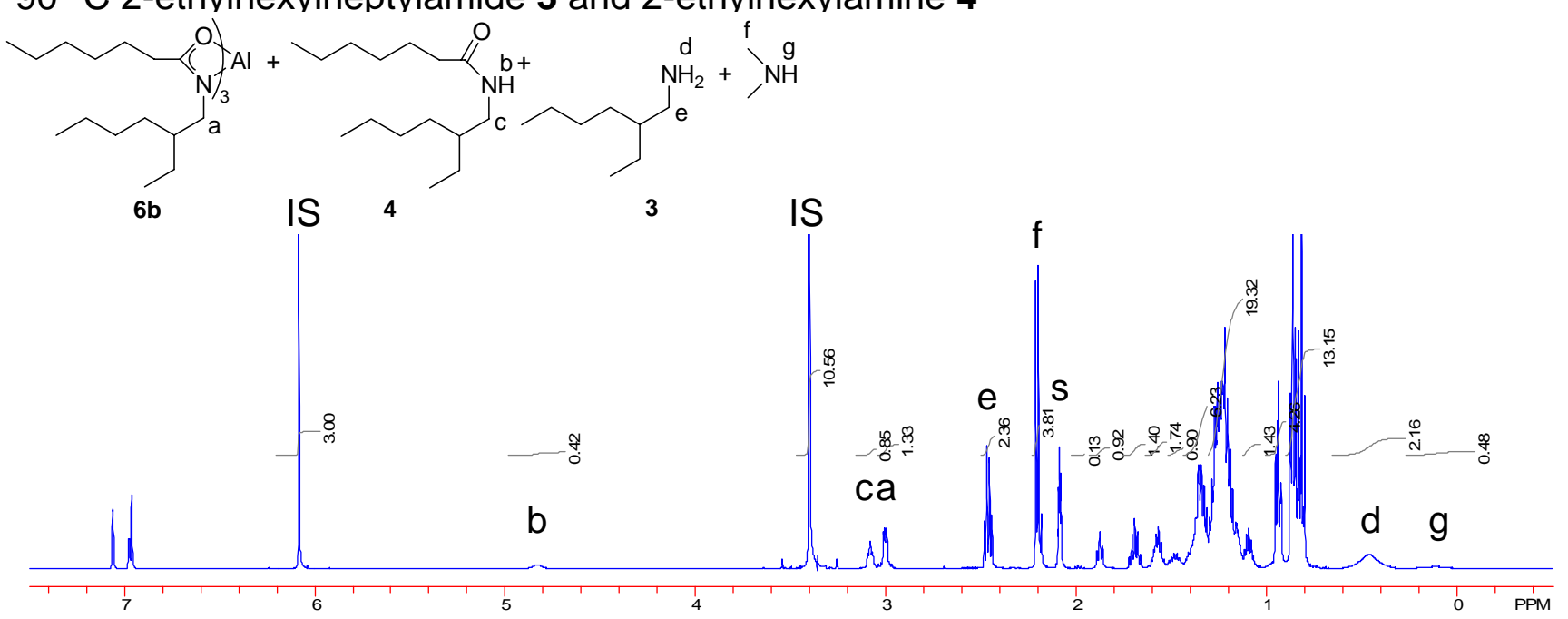

$90{ }^{\circ} \mathrm{C}$ transamidation
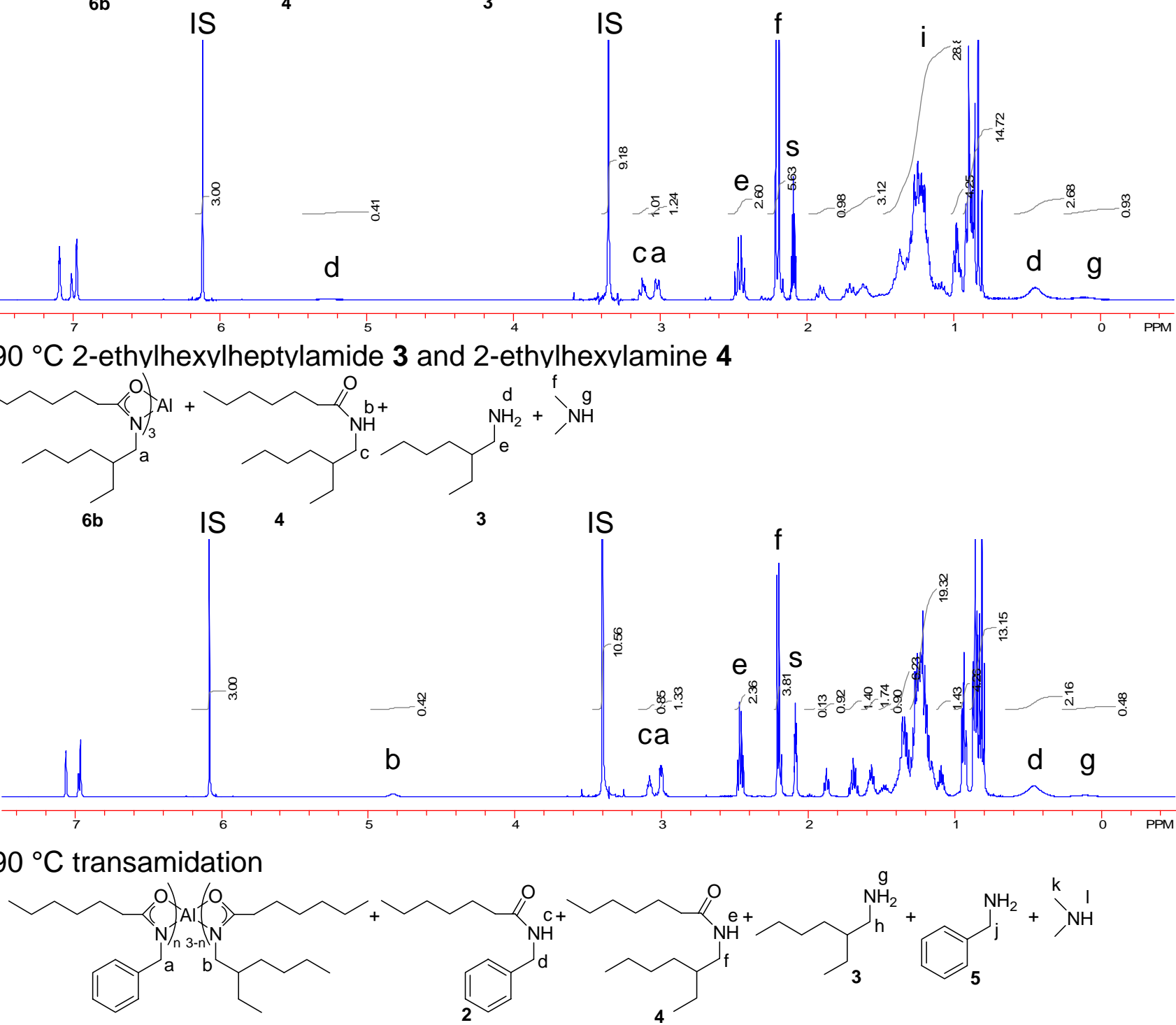

PPM

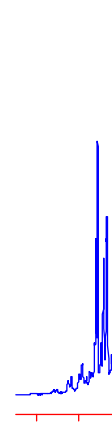

IS<smiles>CCCCCC(=O)NCC(CC)CCCC</smiles><smiles>CCCCCC</smiles><smiles>CCC(CC)C[NH3+]</smiles><smiles>[Y][NH2+]CCc1ccccc1</smiles>

IS

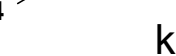

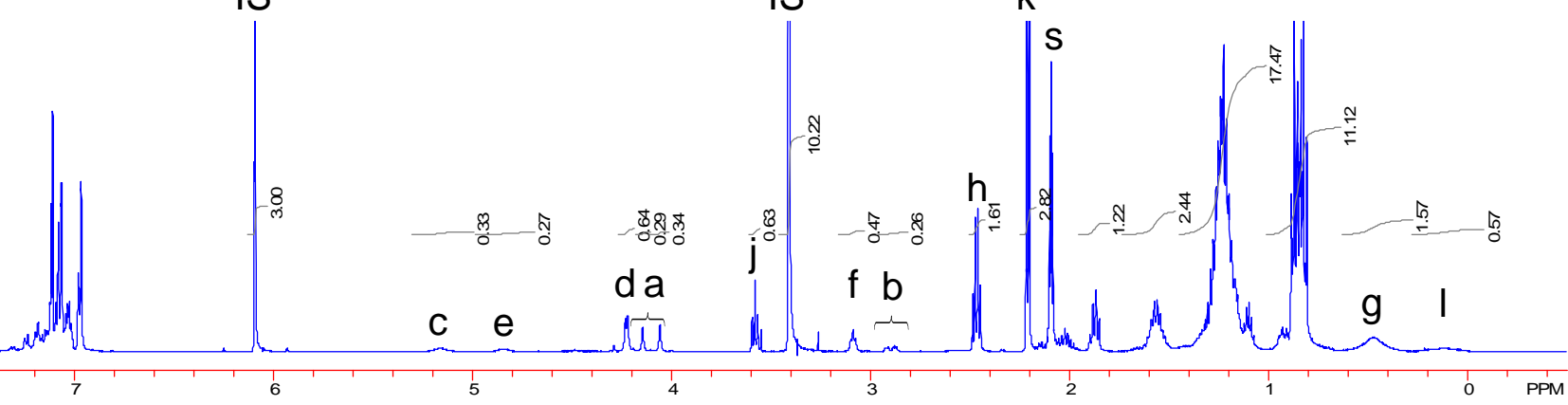

Figure S6. A stacked plot containing two ${ }^{1} \mathrm{H}$ NMR spectra of a degenerate reaction mixture $(\mathbf{1}, \mathbf{3}$, and 4) one shown on the top at $28{ }^{\circ} \mathrm{C}$ and another in the middle at $90{ }^{\circ} \mathrm{C}$ are displayed. The bottom ${ }^{1} \mathrm{H}$ NMR spectra illustrates a sample transamidation reaction mixture at $90^{\circ} \mathrm{C}$. Conditions: amides ( 2 and 3 ) and amines (4 and 5), $0.082 \mathrm{M}\left(1.0 \mathrm{~mL}\right.$ of toluene- $\left.\mathrm{d}_{8}\right) ; 10.0082 \mathrm{M}$ (1.0 mL of toluene- $\left.\mathrm{d}_{8}\right)$. 